\title{
Management of Women Infertility in Tropical Africa: The Experience of the Gynecology Department of University and Hospital Center of Treichville (Abidjan-Cote d'Ivoire)
}

\author{
Jean Marc Lamine Dia*, Eric Bohoussou, Edouard Nguessan, Mouhideen Oyelade, Privat Guié, \\ Simplice Anongba
}

Gynecology Obstetrics, University Hospital of Treichville, Abidjan, Côte d'Ivoire

Email: *jmlaminedia@yahoo.fr

How to cite this paper: Dia, J.M.L., Bohoussou, E., Nguessan, E., Oyelade, M., Guié, P. and Anongba, S. (2017) Management of Women Infertility in Tropical Africa: The Experience of the Gynecology Department of University and Hospital Center of Treichville (Abidjan-Cote d'Ivoire). Open Journal of Obstetrics and Gynecology, 7, 235-244. https://doi.org/10.4236/ojog.2017.72025

Received: January 4, 2017

Accepted: February 21, 2017

Published: February 24, 2017

Copyright $\odot 2017$ by authors and Scientific Research Publishing Inc. This work is licensed under the Creative Commons Attribution International License (CC BY 4.0).

http://creativecommons.org/licenses/by/4.0/ (c) (i) Open Access

\begin{abstract}
Objectives: This study aimed to clarify the etiology of women infertility and describe their management in our service with limited technical equipment. Methodology: We conducted a retrospective and descriptive study on 175 women treated for infertility and followed in the gynecology services of the university Hospital center of Treichville from $1^{\text {st }}$ January 2012 to $31^{\text {st }}$ December 2014. Results: During the study, we recorded 12072 consultations in gynecology including 1582 (13.1\%) cases of infertility, but only 175 cases were selected for this study. The patients had an average age of 31.3 years and an average socio-economic level in general (78.9\%). The etiologies were found in $79.4 \%$ of patients, dominated by classical abnormalities: uterine (fibroids: 41.8\%), hormonal, tubo peritoneal (5\%). We also found some unusual pathologies related to cultural practices (female genital mutilation, caustic stenosis of the vagina). The surgery was performed in several patients, including myomectomy by laparotomy (46.6\%), laparoscopy, hysteroscopy and vaginal surgeries. As to drug treatment, they were various combinations, and the ovarian stimulation practices $(62.3 \%)$ and induction of ovulation (47.2\%) were common. The result of this support has been marked by the occurrence of 74 pregnancies (42.3\%), with the birth of healthy children in the majority of cases (95.9\%). Conclusion: The management of infertile women was frequent and yielded encouraging results despite our limited technical equipment.
\end{abstract}

\section{Keywords}

Women Infertility, Etiologies, Treatment 


\section{Introduction}

Infertility affects $10 \%-20 \%$ of the world's population at reproductive age with a high proportion in Africa [1] [2]. Their management in developed countries is done by modern methods (laparoscopy, medically assisted procreation...) which are rarely available in developing countries. In Africa, there are few infertility specialists, and infertile couples are often supported with limited technical equipment, even in the so-called reference institutions like our University and Hospital Center (CHU). In addition, few publications exist in Africa and particularly in Côte d'Ivoire on the results of this management in this specific context, which justifies our work.

This work aims to clarify the etiology of women infertility and describe their management in our service with a limited technical equipment.

\section{Patients and Methods}

The CHU of Treichville is a level 3center of the health pyramid in our country. And its gynecology department comprises 72 beds and receives about 9000 to 10,000 hospitalizations per year. In this service, we conducted a retrospective and cohort study, from $1^{\text {st }}$ January 2012 to $31^{\text {st }}$ December 2014 (36 months). From $1^{\text {st }}$ January 2012 to $31^{\text {st }}$ December 2013 ( 2 years) we treated many women for infertility, among which some were allowed to have a baby during this period, after normal exploration of their spouses. In this study, those who were regularly monitored during the first year following the date of this permission to have a baby were included. Therefore, the monitoring period is extended until 31 December 2014 for some patients. For those who were able to be pregnant, we learned about the progress of the pregnancies. The parameters studied were the epidemiological characteristics, etiologies, and treatment performed. Data were collected on a survey form from the patient records, tracking sheets and telephone calls. The analyses were performed using Epi Info software, Word and Excel.

\section{Results}

\subsection{Epidemiological Characteristics}

\subsubsection{Frequency}

We recorded 12072 consultations in gynecology from $1^{\text {st }}$ January 2012 to $31^{\text {st }}$ December 2013 including 1582 cases of infertility: a prevalence of $13.1 \%$. However, only 175 cases met our inclusion criteria and were therefore selected for this study.

\subsubsection{Age of Patients}

The women had an average age of 31.3 years (19 - 41 years), and among them, $72 \%$ were under 35 years (126 patients), 21.7\% between 35 and 40 years (38 patients), and $6,3 \%$ over 40 years (11 patients).

\subsubsection{Study Level of Women}

$92.6 \%$ of the women attended school, and $86.3 \%$ reached secondary school level. 


\subsubsection{Socio-Economic Level}

The socioeconomic level was low in 23 patients (13.1\%), average in 138 patients (78.9\%), and higher in 14 patients (8.0\%). We arbitrarily estimated (according to average costs of management) that the socio-economic level was low when their monthly income in the couple was less than $\$ 600$ (US), average when this income was between 600 and $\$ 1,000$ (US), and high when it exceeded $\$ 1000$ (US).

\subsection{Etiologies (Table 1)}

The causes of infertility were unexplained in 36 women (20.6\%) and well identified in 139 patients (79.4\%).

There were 6 cases of vaginal stenosis due to the introduction of caustics in the vagina in an abortive purpose ( 1 case) and for treating fibroids (5 cases).

\subsection{Treatments}

\subsubsection{The Surgical Treatments Performed (Table 2)}

The surgery was performed in 103 patients (exclusively in 29 patients, and associated with drug therapy in 74 patients).

Table 1. Distribution of patients according to the cause of their infertility.

\begin{tabular}{|c|c|c|}
\hline Causes & Population & Frequency (\%) \\
\hline \multicolumn{3}{|l|}{ Uterin } \\
\hline - Fibroids & 58 & 41.8 \\
\hline - Synechiae & 9 & 6.5 \\
\hline - Polyps & 7 & 5.0 \\
\hline \multicolumn{3}{|l|}{ Hormonal } \\
\hline - Ovarians & 17 & 12.2 \\
\hline - Hypothalamo-pituitary & 5 & 3.6 \\
\hline - $\quad$ Mixed & 5 & 3.6 \\
\hline Tubal obstructions & 7 & 5.0 \\
\hline \multicolumn{3}{|l|}{ Cervico vaginal } \\
\hline - Cervical secretion abnormalities & 4 & 2.9 \\
\hline - Infibulation (genital mutilation) & 2 & 1.4 \\
\hline - Vaginal stenosis & 1 & 0.7 \\
\hline Ovariancystsorganic & 5 & 3.6 \\
\hline Endometriosis & 5 & 3.6 \\
\hline \multicolumn{3}{|l|}{ Multiples causes } \\
\hline - Fibroids + vaginal stenosis & 5 & 3.6 \\
\hline - Fibroids + Hyperprolactinemia & 9 & 6.5 \\
\hline Total & 139 & 100.0 \\
\hline
\end{tabular}


Table 2. Distribution of patients according to the type of surgery performed.

\begin{tabular}{|c|c|c|}
\hline Type of surgery & Population & Frequency (\%) \\
\hline \multicolumn{3}{|c|}{ Abdominal surgeryexclusively } \\
\hline \multicolumn{3}{|l|}{ - Myomectomy } \\
\hline - Laparotomy & 48 & 46.7 \\
\hline - Laparoscopy & 19 & 18.4 \\
\hline \multicolumn{3}{|l|}{ - Cystectomy } \\
\hline - Laparotomy & 3 & 2.9 \\
\hline - Laparoscopy & 2 & 1.9 \\
\hline - Tuboplasty by laparoscopy & 7 & 6.8 \\
\hline \multicolumn{3}{|c|}{ Abdominal surgeryassociated to vaginal surgery } \\
\hline \multicolumn{3}{|l|}{ - Myomectomy + vaginal plasty } \\
\hline - Laparotomy + vaginal plasty & 4 & 3.9 \\
\hline - Laparoscopy + vaginal plasty & 1 & 1.0 \\
\hline \multicolumn{3}{|c|}{ Vaginal surgeryexclusively } \\
\hline \multicolumn{3}{|l|}{ - Synechiasurgery } \\
\hline - Hysteroscopy & 3 & 2.9 \\
\hline - Classical curettage & 6 & 5.8 \\
\hline \multicolumn{3}{|l|}{ - Polypremoval } \\
\hline - Hysteroscopy & 3 & 2.9 \\
\hline - Classical curettage & 4 & 3.9 \\
\hline - Vulvovaginal plasty & 3 & 2.9 \\
\hline Total & 103 & 100.0 \\
\hline
\end{tabular}

The surgery was performed by abdominal surgery exclusively in $76.7 \%$ of cases ( 79 patients), by vaginal surgery only in $18.4 \%$ of cases (19 patients) and by both abdominal and vaginal surgeries in $4.9 \%$ of cases ( 5 patients). So, there were a total of 84 patients operated by abdominal surgery including 55 by laparotomy (65.5\%) and 29 by laparoscopy (34.5\%). The uterine cavity was reached by vaginal tract in 16 patients ( 9 cases for synechia and 7 cases for polyps) including 6 by hysteroscopy (37.5\%) and 10 conventional curettage (62.5\%).

The vulvovaginoplasty was performed in 8 patients: 2 cures of infibulation, 1 cure of simple vaginal stenosis, 5 cures of vaginal stenosis associated with myomectomy.

\subsubsection{The Drug Treatments Performed}

Drug treatment was carried out exclusively in 72 patients (36 patients for unexplained infertility, 27 for identified hormonal causes, 4 for confirmed abnormal cervical mucus, and 5 for endometriosis). 
Parallelly to the treatment of those 72 patients, a drug treatment was associated to the surgery in 74 patients.

Drug treatments performed in these 146 patients were variously associated and included: bromocriptin (30.8\% of patients), antibiotics (18\% of patients), progesterone ( $25.3 \%$ of patients), the estrogen (13\% of patients), clomiphene citrate (6.3\% of patients), gonadotropins ( $47.2 \%$ of patients).

\subsection{Treatment Results (Table 3)}

Finally, after the management of our 175 patients, we obtained a total of 74

Table 3. Distribution of pregnancies achieved in 103 patients operated.

\begin{tabular}{|c|c|c|}
\hline Pregnancyoccurs & Population & Frequency (\%) \\
\hline \multicolumn{3}{|l|}{ Aftermyomectomy } \\
\hline - SpontaneousPregnancies & 22 & 38.8 \\
\hline - Inducedpregnancies & 11 & 16.4 \\
\hline - Lack of pregnancy & 34 & 50.8 \\
\hline - Total & 67 & 100.0 \\
\hline \multicolumn{3}{|l|}{ After cystectomies } \\
\hline - SpontaneousPregnancies & 0 & 0.0 \\
\hline - Inducedpregnancies & 1 & 20.0 \\
\hline - Lack of pregnancy & 4 & 80.0 \\
\hline - Total & 5 & 100.0 \\
\hline \multicolumn{3}{|l|}{ Aftertubalplasty } \\
\hline - SpontaneousPregnancies & 0 & 0.0 \\
\hline - Inducedpregnancies & 0 & 0.0 \\
\hline - Lack of pregnancy & 7 & 100.0 \\
\hline - Total & 7 & 100.0 \\
\hline \multicolumn{3}{|l|}{ Aftermyomectomy + vaginal plasty } \\
\hline - SpontaneousPregnancies & 1 & 20.0 \\
\hline - Inducedpregnancies & 0 & 0.0 \\
\hline - Lack of pregnancy & 4 & 80.0 \\
\hline - Total & 5 & 100.0 \\
\hline \multicolumn{3}{|l|}{ Aftersynechiasurgery } \\
\hline - SpontaneousPregnancies & 1 & 11.1 \\
\hline - Inducedpregnancies & 1 & 11.1 \\
\hline - Lack of pregnancy & 7 & 77.8 \\
\hline - Total & 9 & 100.0 \\
\hline \multicolumn{3}{|l|}{ Afterpolypremoval } \\
\hline - SpontaneousPregnancies & 3 & 42.9 \\
\hline - Inducedpregnancies & 1 & 14.2 \\
\hline - Lack of pregnancy & 3 & 42.9 \\
\hline - Total & 7 & 100.0 \\
\hline \multicolumn{3}{|l|}{ After vaginal plasty } \\
\hline - SpontaneousPregnancies & 2 & 66.7 \\
\hline - Inducedpregnancies & 0 & 0.0 \\
\hline - Lack of pregnancy & 1 & 33.3 \\
\hline - Total & 3 & 100.0 \\
\hline
\end{tabular}


pregnancies (42.3\%) including 68 single pregnancies and 6 twins (all occurred after ovarian stimulation and ovulation induction). These pregnancies were obtained in 43 patients who were operated ( $41.7 \%$ of operated patients) and in 31 non-operated women (43.1\% non-operated patients). Among the patients who had an unexplained infertility, we obtained 20 pregnancies.

In the operated patients, 43 pregnancies occurred spontaneously in $67.4 \%$ of cases (29 patients) and induced in 32.6\% (14 patients).

\subsection{Outcome of the Pregnancy}

The evolution of the 74 pregnancies, has been marked by three abortions and 71 live births (including 6 prematures and 65 newborns at term). All pregnancies achieved in patients operated led to term without incident, and deliveries were made by cesarean section in $88.6 \%$ of cases.

\section{Discussion}

During the study period we had 1582 consultations for infertility, but only 175 cases met our inclusion criteria and were therefore selected for this study, which could lead tolimitations in ourresults.

\subsection{Epidemiological Characteristics}

\subsubsection{Infertility Prevalence}

The prevalence of infertility in our series was $13.1 \%$. It is close to those found in the African and world literature: $10 \%$ to $20 \%$ [1] [3] [4]. This finding reflects the importance of infertility in our developing countries often masked by rapid population growth.

\subsubsection{The Age of the Patients}

The average age of our patients was 31.3 years (range 19 - 41 years), closer to those found in other African countries, mainly by Boudhraain Tunisia (33.33 years) and Bang in Gabon (34.9 years) [3] [4] And the majority of our patients had an age below 35 years (72\%), therefore being in ideal period to resolve their infertility problem. For beyond that age, they will enter the limits of ovarian reserves.

\subsubsection{Study and Socio-Economic Levels}

The majority of our patients (92.6\%) had a satisfactory level of education for understanding the management (secondary and higher levels), but they had an average socio-economic level in the couple in general (78.9\%), which constituted an obstacle to the treatment of some patients.

\subsection{Causes of Infertility}

The causes of infertility found in our study were dominated by uterine factors, mainly fibroids $(41.8 \%)$. These patients generally had polymyomatous uterus with changes in the uterine cavity, without other associated factors that may explain their infertility. Also, several authors in the world and particularly in Afri- 
ca, have reported high incidence of fibroids in their patients' infertility [5]-[10]. Fibroids are indeed becoming source of infertility, depending on their location and size, and in our developing countries where there is no social security, it is still common to find patients carriers of large fibroids affecting their fertility.

The second cause of infertility found in our study population had a hormonal origin, particularly ovarian disorders (12.2\%). Like us, different authors have found that ovarian abnormalities (type of dystrophy) were one of the main causes of infertility in women [10] [11] [12].

Regarding tubal causes, they were found in our population but at a lower frequency (5.0\%) than those reported in African literature mainly. Indeed in Africa several publications have reported that tubal abnormalities were one of the main causes of infertility in women with rates above $20 \%$, due to infection [13] [14]. But note that our study was limited only to patients who actually received treatment and were followed for 1 year, excluding patients who had tubal infertility but who have not been treated or whom we have lost of view. As for other common causes of female infertility, they were also encountered in our series: organic ovarian cysts (3.6\%), endometriosis (3.6\%), abnormal cervical mucus $(2.8 \%)$.

Moreover, some infertility causes related to some African cultural practices were highlighted in our study: the effects of genital mutilation ( 2 cases) and vaginal stenosis (6 cases). The case of vaginal stenosis was due to the introduction of traditional products vaginally in an abortive goal ( 1 case) or to treat uterine fibroids (5 cases). Caustic stenosis of the vagina becomes exceptional in developed countries for over 30 years [15] unlike our underdeveloped countries where they are still found today. Seni, in our country, reported a series of 21 cases of vaginal stenosis, met in 20 years, an average of one case per year [16].

Finally, infertility was unexplained in $20.6 \%$ of our patients in context with limited technical equipment. Further exploration would certainly permit to find some causes passed unnoticed.

\subsection{Treatment Characteristics}

\subsubsection{Surgical Treatment}

Surgical treatment was performed in the majority of our patients, and was dominated by myomectomy by laparotomy $(46.7 \%)$. The common practice of laparotomy in our context is explained by the fact that patients often consult late at stages where laparoscopy has no place, or because they are limited financially to meet the costs of laparoscopy in a private institution (because our service has no laparoscopy unit). Nevertheless, some patients could benefit from laparoscopy and hysteroscopy performed in other structures before returning to us to continue the treatment.

After the surgery performed, we generally allow the occurrence of pregnancy in an average delay of two months after an endocavitary surgery (curettage, hysteroscopy) and 6 months after myomectomy. If after 4 ovarian cycles there is no spontaneous pregnancy we perform an ovarian stimulation with or without 
ovulation induction on the 3 following cycles. If that fails, we send them to specialized centers to medical aid for procreation (MAP) for further management (which are private centers with non accessible costs for our patients).

This approach aims to get pregnant within not too long nor too short delay after surgery, in order to avoid complications. The delay should not be too long in order to get pregnant before the installation of possible postoperative aftermaths (adhesion, synechia) that could be a new source of infertility because second-look laparoscopy indications (to release these adhesions and synechia) remain limited to patients who are able to pay the cost of this surgery. The delay should not be too short to prevent uterine ruptures once the pregnancyis acquired.

Concerning myomectomy we commonly practiced in our study, in the literature there is no consensus on the time limit before the occurrence of pregnancy. Soriano and D'Ercole believe that there are no sufficient objective arguments for recommending a particular time between myomectomy and the occurrence of pregnancy [17] [18].

Finally, all vulvovaginal lesions caused by caustic stenosis or mutilation aftermaths were made vaginally in our study because this is accessible by vaginal surgery.

\subsubsection{Drug Treatment}

Many patients (146) received drug treatment. Ovarian stimulation and ovulation induction have been frequently practiced in our patients. They were systematically indicated in all women who have unexplained infertility and in those who have been operated and who did not have spontaneous pregnancy after an attempt on 3 ovarian cycles. As for other types of medication (bromocriptine, antibiotic, progesterone), they have been indicated according to the identified etiology.

\subsection{Pregnancies after Treatment}

In patients who underwent abdominal surgery, regardless of age, spontaneous pregnancies were more common after myomectomy (31.3\%). In the literature, it is reported that after myomectomy by laparotomy for infertility, spontaneous pregnancy rate is higher than $50 \%$ in patients under 35 years and under $50 \%$ in older women [19] [20].

Regarding patients who had vaginal surgery, pregnancies were more common in those who have had a vaginal plasty (2 patients in 3). Indeed, 2 patients had infibulation type of genital mutilation aftermaths, which actually prevented normal sex with their spouses. As for the cases of plasty for caustic stenosis, failures were mainly due to relapses which are very common in these cases. In nonoperated patients, after 1 year follow-up, we recorded pregnancies in 31 patients including 6 twin pregnancies.

Concerning the outcome of pregnancies, the evolution of the 74 pregnancies obtained was marked by three abortions and 71 live births (including 6 prema- 
tures and 65 newborns at term). All the pregnancies obtained in the operated patients led to term pregnancy without any incidents and delivery was made by cesarean in most cases. Finally, patients who had twin pregnancies gave birth to healthy preterm infants.

\section{Conclusion}

The consultations for infertility were common in our service (13.1\%) and mainly concerned patients with an average socio-economic level. The management is usually made by conventional methods (such as myomectomy by laparotomy, ovarian stimulation) but some patients have benefited from modern methods (laparoscopy, hysteroscopy, ovulation induction). Pregnancy rates obtained were encouraging relatively to our limited technical equipment. However for best results, we recommend our authorities to raise the level of this technical equipment in our public institutions, providing them with laparoscopic unit and center of medical aid for procreation.

\section{Funding}

None.

\section{Conflict of Interest}

None.

\section{References}

[1] Boivin, J., Bunting, L., Collins, J.A. and Nygren, K.G. (2007) International Estimates of Infertility Prevalence and Treatment-Seeking: Potential Need and Demand for Infertility Medical Care. Human Reproduction, 22, 1506-1512. https://doi.org/10.1093/humrep/dem046

[2] Larsen, U. (2000) Primary and Secondary Infertility in Sub-Saharan Africa. International Journal of Epidemiology, 29, 285-289.

https://doi.org/10.1093/ije/29.2.285

[3] Boudhraa, K., Jellouli, M.A., Kassaoui, O., Ben Aissia, N., Ouerhani, R., Triki, A., et al. (2009) Role of the Hysteroscopy and Laparoscopy in Management of the Female Infertility: About 200 Cases. La Tunisie Médicale, 87, 55-60.

[4] Bang Ntamack, J.A., Mayi-Tsonga, S., Ole Sima, B. and Meye, J.F. (2009) Pregnancy after Myomectomy in Libreville, Gabon. Wink Mother Child Health, 6, 1101-1106.

[5] Ganji, S., Adisso, S., Atrevi, N., et al. (2013) Etiological Diagnosis of Lesions of Secondary Infertility in Cotonou: Role of Hysterosalpingography and Pelvic Ultrasound. Journal of Applied Biosciences, 68, 5349-5355.

[6] Oliveira, F.G., et al. (2003) Uterine Cavity Findings and Hysteroscopic Response in Patients Undergoing in Vitro Fertilization-Embryo Transfer Who Repeatedly Can Not Conceive. Fertility Sterility, 80, 1371-1375. https://doi.org/10.1016/j.fertnstert.2003.05.003

[7] Payson, M., Leppert, P. and Segars, J. (2006) Epidemiology of Myomas. Obstetrics \& Gynecology Clinics of North America, 33, 1-11. https://doi.org/10.1016/j.ogc.2005.12.004

[8] Bajekal, N. and Li, T.C. (2000) Fibroids, Infertility and Pregnancy Wastage. Human 
Reproduction Update, 6, 614-620. https://doi.org/10.1093/humupd/6.6.614

[9] Kouamé, N., N’Goan-Domoua, A.M., Konan, N., et al. (2012) Contribution of Transvaginal Ultrasound Associated with Hysterosalpingography in Etiological Research of Female Infertility in Abidjan (Côte d'Ivoire). African Journal of Reproductive Health, 16, 43-49.

[10] Belley, P.E., Tchente, N.C., Nguemgne, C., et al. (2015) Female Infertility to the General Hospital in Douala: Epidemiological and Radiological Aspects (about 658 Cases). Journal Africain d' Imagerie Médicale, 2, 16-23.

[11] Jose-Miller, A.B., Boyden, J.W. and Frey, K.A. (2007) Predominance of Ovarian Pathologies as Etiologies of Hypofertilités. Infertility. American Family Physician, 75, 849-856.

[12] Lahady, R., Daodo, H., Razakamaniraka, J. and Andrianjafimanana, C. (2000) Hysterosalpingography and Tubalsterility. Médecine d'Afrique Noire, 47, 252-255.

[13] Fiadjoe, M.K., Adjenou, V., Kolani, A.D. and Egah, K.K. (2012) Tubal Infertility in Africa. Updated CNGOF, 36, 641-656.

[14] Cates, W. (1985) Worldwide Patterns of Infertility: Is Africa Different? The Lancet, 2, 596-598. https://doi.org/10.1016/S0140-6736(85)90594-X

[15] Erny, R. and Tramier, D. (1981) Acquired Contracting of the Vulva and the Vagina. EMC, Paris.

[16] Séni, K., Horo, A.G., Koffi, A., Aka, K.E., Fomba, M. and Koné, M. (2016) Acquired Caustic Vagina Stenosis: Surgical Outcomes of 21 Cases. Obstetrics and Gynecology, 44, 141-145.

[17] Soriano, D., Dessolle, L., Poncelet, C., Benifla, J.L., Madelenat, P. and Darai, E. (2003) Pregnancy Outcome after Laparoscopic and Laparo Converted Myomectomy. European Journal of Obstetrics \& Gynecology and Reproductive Biology, 108, $194-$ 198. https://doi.org/10.1016/S0301-2115(02)00436-0

[18] D’Ercole, C., Carcopino, X., Haumonte, J.B. and Kayem, G. (2012) Idealdelay between Uterinesurgery and Pregnancy (Including Caesarean Section). Updated CNGOF, 36, 89-104.

[19] Vercellini, P., Maddalena, S., De Giorgi, O., Pesole, A., Ferrari, L. and Crosignani, P.G. (1999) Determinants of Reproductive Outcome after Abdominal Myomectomy for Fertility. Fertility and Sterility, 72, 109-114. https://doi.org/10.1016/S0015-0282(99)00200-9

[20] Campo, S., Campo, V. and Gambadauro, P. (2003) Reproductive Outcome before and after Laparoscopic or Abdominal Myomectomy for Subserous or Intramural Myomas. European Journal of Obstetrics \& Gynecology and Reproductive Biology, 110, 215-219. https://doi.org/10.1016/S0301-2115(03)00159-3 
Submit or recommend next manuscript to SCIRP and we will provide best service for you:

Accepting pre-submission inquiries through Email, Facebook, LinkedIn, Twitter, etc. A wide selection of journals (inclusive of 9 subjects, more than 200 journals)

Providing 24-hour high-quality service

User-friendly online submission system

Fair and swift peer-review system

Efficient typesetting and proofreading procedure

Display of the result of downloads and visits, as well as the number of cited articles Maximum dissemination of your research work

Submit your manuscript at: http://papersubmission.scirp.org/

Or contact ojog@scirp.org 